\title{
The bone densitometry is normal in Turner syndrome prepubertal patients after height age correction
}

Renata Thomazini Dallago 1

iD https://orcid.org/0000-0002-0754-0718

Denise Barbieri Marmo 2

(iD https://orcid.org/0000-0001-5227-2452

André Moreno Morcillo 3

iD https://orcid.org/0000-0002-2088-972x

Gil Guerra-Júnior 4

(iD https://orcid.org/0000-0002-2991-7678

Allan de Oliveira Santos 5

iD https://orcid.org/0000-0002-9192-6946

\author{
Marcus Vinicius Galon 6 \\ iD https://orcid.org/0000-0003-3137-7751 \\ Sofia Helena Valente de Lemos-Marini 7 \\ (iD) https://orcid.org/0000-0002-8289-5703
}

${ }^{1}$ Hospital de Clínicas. Universidade Estadual de Campinas. Rua Tessália Vieira de Camargo, 126. Cidade Universitária. Campinas, SP, Brasil. CEP: 13.083-887. E-mail: renatatdallago@gmail.com

2,3,4,7 Departamento de Pediatria. Faculdade de Ciências Médicas. Universidade Estadual de Campinas. Campinas, SP, Brasil.

5 Divisão de Medicina Nuclear. Departamento de Radiologia. Hospital de Clínicas. Universidade Estadual de Campinas. Campinas, SP, Brasil.

${ }^{6}$ Radiologia e Diagnóstico por Imagem. Hospital Alvorada. São Paulo, SP, Brasil.

\begin{abstract}
Objectives: to evaluate the bone mass in prepubertal patients with Turner Syndrome (TS) according to height age (HA) and verify the influence of karyotype and adiposity.

Methods: retrospective and analytical study of prepubertal TS patients. The variables analyzed were: karyotype, age at bone densitometry (BD), height, body mass index (BMI) and $B D$ result. The result of the $B D$ was corrected using $H A$. BMI and $B D$ were calculated on $Z$ score for chronological age (CA) and for $H A$.

Results: thirty-seven prepubertal patients were selected and after exclusion criteria, 13 cases between 10 and 13 years old were included in the study. The BD for HA was significantly higher than for $C A(0.39 \pm 1.18 x-1.62 \pm 1.32)$, without karyotype $(p=0.369)$ and $B M I$ $(p=0.697)$ influence.

Conclusion: prepubertal TS patients present normal BD when corrected for HA, without influence of karyotype and BMI.

Key words Turner syndrome, Bone density, Densitometry
\end{abstract}

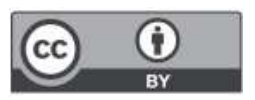




\section{Introduction}

Turner Syndrome (TS) is characterized by the presence of an intact $X$ chromosome and the complete or partial loss of the second sex chromosome (X or Y) and is associated with skeletal abnormalities that include short stature, in addition to other clinical manifestations such as characteristic physical features, ovarian failure, early hearing loss, congenital cardiovascular changes, and a higher frequency of other diseases such as hypothyroidism and celiac disease. ${ }^{1}$ It has a prevalence of 1 in every 2,000 female live births. ${ }^{2} 45$, $\mathrm{X}$ monosomy is present in around $40 \%$ to $50 \%$ of cases, while the other cases present mosaicism with one or more additional cell lines $(\mathrm{X}$ or $\mathrm{Y})$ and/or structural alterations (X or Y). 1,3

The etiology and mechanism of bone fragility in TS have not yet been fully elucidated and may be associated to intrinsic bone defects induced by chromosomal alteration that are exacerbated by hormonal factors. $2-4$ Patients with TS have a $25 \%$ increase in the risk of fractures. 5,6 Normal bone architecture is influenced by the continuous process of bone modeling and remodeling, 5 the regulation of chondrocytes is complex and involves endocrine factors (growth hormone, estrogen, thyroid hormone), and local/paracrine factors. 6

Bone densitometry (BD) using dual-energy Xray absorptiometry (DXA) has been used since the 1980 s to assess bone mineral content, but it only analyzes the two-dimensional bone measurement $(\mathrm{g} / \mathrm{cm} 2)$ and not its actual volume $\left(\mathrm{g} / \mathrm{cm}^{3}\right)$. This is the most used method worldwide, justified by its easiness, speed, reproducibility, precision, safety, low cost, and availability to predict fracture risk. ${ }^{7}$

In children, the interpretation of the BD must be performed using the Z-score parameter (it evaluates the mean of the normal population of the same sex and age). In patients with short stature, it is necessary to correct the study values for bone age or, as more recently recommended, for height age. $8-10$

The diagnosis of low bone mass is made when a Z-score of less than two standard deviations $(<-2.0)$ for age is evidenced and, for the diagnosis of osteoporosis, it is necessary that the child has fractured one or more vertebrae in the absence of local disease or high-energy trauma or having a significant history of previous fractures associated with low bone density. 11

Several studies have shown that patients with TS have low BD when evaluated via studies with DXA. However, the studies have limitations because they use a two-dimensional method and patients with short stature, such as in TS, may receive an underestimated result with decreased $\mathrm{BD}$, which can be corrected for height or for volumetric $\mathrm{BD}$ $\left(\mathrm{g} / \mathrm{cm}^{3}\right) .5,6,12$

Bone mineral density (BMD) is believed to be influenced by modifiable genetic and environmental factors such as adiposity, hormone levels, sun exposure, blood pressure, physical activity, and diet. 13

Therefore, this study aimed to evaluate BD in patients with TS with correction for age and height and to verify the interference of karyotype and BMI.

\section{Methods}

This is a descriptive and analytical cross-sectional study and retrospective analysis of medical records of patients diagnosed with TS, followed at the Pediatric Endocrinology Outpatient Clinic at the Teaching Hospital of the University of Campinas (HC-Unicamp - Portuguese acronym). This outpatient clinic at HC-Unicamp monitors patients with Turner Syndrome with biannual consultations for treatment and guidance, seeking to improve their quality of life with modifiable factors such as diet and physical activity.

Inclusion criteria were: patients diagnosed with $\mathrm{TS}$, in the prepubertal stage (aiming to homogenize the sample, avoiding hormonal interference and the characteristic events of puberty in bone mass); with BD evaluation performed at the HC-Unicamp, using the Hologic Discovery Wi bone densitometer (S/N83901).

The exclusion criteria were the use of medications aimed to improve growth (such as growth hormone) and the presence of chronic disease or use of medications that could interfere with bone metabolism.

The diagnosis of TS was confirmed through the karyotype with evaluation of at least 20 metaphysis. The variables analyzed were: karyotype, length of follow-up at the service, age at BD; height and BMI obtained in the medical appointment closest to the performance of the BD and the BD result in Z-score. To evaluate the results without the bias of short stature, the BD Z-score was corrected using, instead of chronological age (CA), the height age (HA), that is, using as age that corresponding to the 50 percentile of the measured height. 14

The BMI in Z-score was used to assess adiposity. SPSS software, version 16.0 was used for data statistical analysis. The mean, standard deviation, minimum, maximum, median, and interquartile range of quantitative variables were determined. The dependent variables were: BD Z-score for CA and 
$\mathrm{HA}$; to compare the results of the Z-score for both BD-CA and BD-HA, the Wilcoxon test was used. To compare the distribution of BDs in relation to karyotype and BMI, the Mann-Whitney test was used and the probabilities were calculated using the bootstrap technique, Monte Carlo method, from 10,000 samples. A 5\% significance level was used for results interpretation.

\section{Results}

In this study, 37 patients aged 8-13 years were selected. Among them, 13 were excluded for not having undergone any $\mathrm{BD}$ at the $\mathrm{HC}$-Unicamp, eight for having used growth hormone, two patients for having spontaneous puberty at the time of the BD assessment, and one patient with an associated diagnosis of non-classic Congenital Adrenal Hyperplasia and uses steroids. Thus, 13 patients were included in the study, four of whom had more than one BD assessment. Therefore, exams performed between the ages of 10 and 13 were selected in order to homogenize the study. Patients included in the study had follow-up at the service for an average period of eight years.

Regarding the chromosomal constitution, six individuals (46.1\%) had 45,X karyotype and seven (53.8\%) had mosaicism with a 46,XX normal lineage and/or with structural alterations of the $X$ chromosome. None had Y chromosome intact or not. The CA at the time of BD was significantly higher $(p<0.001-$ Wilcoxon test $)$ compared to HA (12.5 \pm $1.05 \times 9.05 \pm 1.20)$ (Table 1)

The mean Z-score of the BD-CA was significantly lower $(p<0.001$; Wilcoxon test $)$ than that of the BD-HA $(-1.62 \pm 1.32 \times 1.39 \pm 1.18)$ (Table 1)(Figure 1).

The mean of the BD-CA Z-score did not differ significantly ( $p=0.525$; Mann-Whitney test) in rela- tion to $45, \mathrm{X}$ and other karyotypes $(-1.48 \pm 1.25 \times-$ $1.74 \pm 1.46)$ (Table 2), the same occurring for BDHA ( $p=0.369-$ Mann-Whitney test $)(0.70 \pm 0.51 \times$ $0.13 \pm 1.54$ ) (Table 2).

The mean of the Z-score of the BD-CA did not differ significantly ( $p=0.734$; Mann-Whitney test) in relation to the median (group above $v s$. group below) of the BMI Z score $(-1.48 \pm 0.76 \times-1.74 \pm 1.72)$ (Table 3), the same occurring for BD-HA $(p=0.697$; Mann-Whitney test) $(0.63 \pm 0.46 \times 0.19 \pm 1.57)$ (Table 3).

\section{Discussion}

The results found in this study indicate that, although patients with TS present compromised Z-score of $\mathrm{BD}$ for $\mathrm{CA}$ when correction for $\mathrm{HA}$ is performed, the results are within the expected range.

The association between TS and low bone mineral density/osteoporosis is still controversial in the literature. The low bone mass found in this group when evaluated using BD for CA seems to be associated with short stature, as described in other studies, 6,15 since, when the result was corrected using HA, no patient was found with low BD. The same has been described in other studies that performed the correction of $\mathrm{BD}$ for HA.16,17 However, other authors have already reported that the $\mathrm{BD}$ alteration remained even after correction for $\mathrm{HA}$ and suggested that the risk of osteoporosis is greater in patients with TS due to early ovarian failure and possibly due to bone alterations resulting from haploinsufficiency of the gene SHOX.18

In our study, the two groups of karyotypes (45,X and karyotypes with mosaicism) were compared and no differences were found regarding the $\mathrm{Z}$-score for height, BMI and BD results, which is in agreement with the literature. 16,19,20 Short stature in TS can be largely attributed to the haploinsufficiency of the

Table 1

Distribution of chronological age (CA) and height age (HA) and Bone Densitometry (BD) by CA and HA of 13 prepubertal patients with Turner Syndrome.

\begin{tabular}{lcccc}
\hline & \multicolumn{3}{c}{ Age (years) } & BD (Z-score) \\
\cline { 2 - 5 } & CA & HA & CA & HA \\
\hline Average & 12.54 & 9.05 & -1.62 & 0.39 \\
Minimum & 10.00 & 7.40 & -3.90 & -2.00 \\
Maximum & 13.90 & 11.00 & 0.70 & 2.40 \\
Median & & & -1.50 & 0.70 \\
$p$ & 0.001 (teste de Wilconox) & $<0.001$ (teste de Wilconox) \\
\hline
\end{tabular}


Distribution of BD-CA and BD-HA in 13 prepubertal patients with Turner Syndrome.

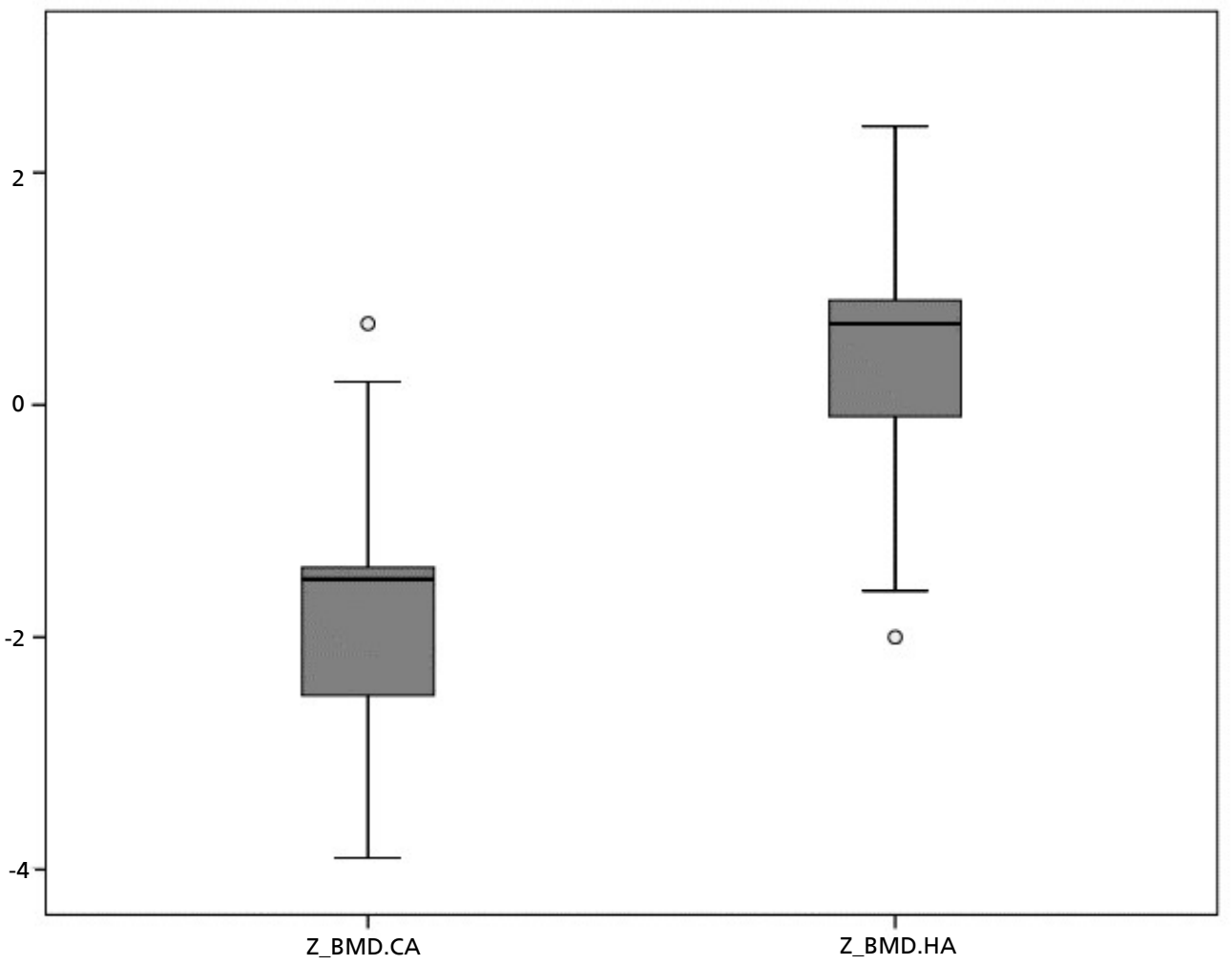

$p<0.001$ Wilcoxon test probability.

Table 2

Z-score of bone densitometry for chronological age (CA) and height age (HA) in relation to karyotype.

\begin{tabular}{lcc} 
Karyotype & Distribution of bone densitometry in relation to karyotype \\
\hline $45, \mathrm{X}$ & Z_BMD CA* $^{*}$ & Z_BMD HA** \\
$\mathrm{N}$ & 6 & 6 \\
Average & -1.48 & 0.70 \\
Minimum & -2.90 & -0.10 \\
Median & -1.40 & 0.80 \\
Maximum & 0.70 & 1.40 \\
Standard deviation & 1.25 & 0.51 \\
Mosaicism & & \\
$\mathrm{N}$ & 7 & 7 \\
Average & -1.74 & 0.13 \\
Minimum & -3.90 & -2.00 \\
Median & -1.80 & 0.30 \\
Maximum & 0.20 & 2.40 \\
Standard deviation & 1.46 & 1.54 \\
& & \\
\hline
\end{tabular}

${ }^{*} p=0.525$ (Mann-Whitney test); ** $p=0.369$ (Mann-Whitney test). 
Distribution of the bone densitometry Z-score in relation to BMI (median cut-off point $=0.61$ ) for CA and $\mathrm{HA}$ of 13 prepubertal patients with Turner Syndrome.

\begin{tabular}{|c|c|c|}
\hline \multirow{2}{*}{$\begin{array}{l}\text { Median Z_BMI } \\
>0.61\end{array}$} & \multicolumn{2}{|c|}{$\begin{array}{l}\text { Distribution of } B D \text { in relation to } B M I \text { using as a cutoff } \\
\text { point the median }=0.61 \text { for } C A \text { and } H A\end{array}$} \\
\hline & Z BMD CA* & $\mathrm{Z} B M D \mathrm{HA}^{* *}$ \\
\hline $\mathrm{N}$ & 6 & 6 \\
\hline Average & -1.48 & 0.63 \\
\hline Minimum & -2.50 & -0.10 \\
\hline Median & -1.45 & 0.75 \\
\hline Maximum & 0.720 & 1.20 \\
\hline Standard deviation & 0.76 & 0.46 \\
\hline \multicolumn{3}{|l|}{$\leq 0.61$} \\
\hline $\mathrm{N}$ & 7 & 7 \\
\hline Average & -1.74 & 0.19 \\
\hline Minimum & -3.90 & -2.00 \\
\hline Median & -1.80 & 0.40 \\
\hline Maximum & 0.70 & 2.40 \\
\hline Standard deviation & 1.72 & 1.57 \\
\hline
\end{tabular}

${ }^{*} p=0.734$ (Mann-Whitney test); ${ }^{*} p=0.697$ (Mann-Whitney test); $\mathrm{BD}=$ bone densitometry; $\mathrm{BMI}=$ body mass index; $\mathrm{CA}=$ chronological age; $\mathrm{HA}=$ height age.

SHOX gene, which has been correlated with short stature and bone phenotype in TS.3,16,20,21

There are studies that describe an increased risk of fractures associated with the syndrome, however with an inconclusive relationship with $\mathrm{BD}, 5,12,21$ since they present normal BD Z-score values after correction for HA, although clinically they present an increased risk for fractures. 16

Although some studies have already demonstrated a positive relationship between weight and BMD, 22,23,24 in our study with BMI, no difference was observed between groups with higher or lower BMI values. These findings are similar to those of Costa et al. ${ }^{19}$ Alghadir et al. ${ }^{13}$ estimate a variation in bone mineral density (BMD) from $60 \%$ to $80 \%$, that is influenced not only by ethnic and genetic factors, but also by modifiable environmental factors such as adiposity, hormone levels, sun exposure, blood pressure, physical activity, and diet. Body weight is a factor that would have a positive influence on BMD, although this relationship is not linear, as even in obese patients, BMD can be compromised.22-24

The limitations of our study were the small sample and being a retrospective study, and not having a control group, which was partially compensated by the fact that all BD variables were analyzed by Z-score.

The strengths of the study were a group of patients in a limited age group, all prepubescent, and the fact that, because they were followed by the same group with specific guidelines on nutrition and physical activity, some of the factors that could negatively affect the mass bone were minimized.

There was no confirmed evidence of low bone mass in this group of patients with TS. Lower BD values are associated with short stature bias and when corrected for HA values are within normal limits. Karyotype and BMI do not modify the BD result in prepubertal patients with TS.

\section{Authors' contribution}

Dallago RT, Lemos-Marini SHV and Guerra-Junior $\mathrm{G}$ contributed to the planning, preparation and review of the study. Data collection was performed by Dallago RT, Marmos DB and Galon MV. Morcillo AM assisted in the statistical analysis. For help with techniques and with the densitometry device, we have the collaboration of Santos AO. The manuscript was written and revised by Dallago RT and Lemos-Marini SHV. All authors approved the final version of the manuscript and are publicly responsible for the content of the article. 


\section{References}

1. Gravholt CH, Andersen NH, Conway GS, Dekkers OM, Geffner ME, Klein KO, et al. Clinical practice guidelines for the care of girls and women with Turner syndrome: Proceedings from the 2016 Cincinnati International Turner Syndrome Meeting. Eur J Endocrinol. 2017; 177 (3): G1-70.

2. Cintron D, Rodriguez-Gutierrez R, Serrano V, LatortueAlbino P, Erwin PJ, Murad MH. Effect of estrogen replacement therapy on bone and cardiovascular outcomes in women with turner syndrome: a systematic review and meta-analysis. Endocrine. 2017; 55 (2): 366-75.

3. Faienza MF, Ventura A, Colucci S, Cavallo L. Bone Fragility in Turner Syndrome : Mechanisms and Prevention Strategies. Front Endocrinol (Lausanne). 2016; 7: 1-8.

4. Soucek O, Matyskova J, Anliker E, Toigo M, Hlavka Z, Lebl $\mathrm{J}$, et al. The muscle-bone interaction in Turner syndrome. Bone. 2015; 74: 160-5.

5. Soucek O, Lebl J, Snajderova M, Kolouskova S, Rocek M, Hlavka Z, et al. Bone geometry and volumetric bone mineral density in girls with Turner syndrome of different pubertal stages. Clin Endocrinol (Oxf). 2011; 74 (4): 44552.

6. Cleemann L, Holm K, Kobbernagel H, Skouby SO, Kristensen B, Smedegaard H, et al. Normal tempo of bone formation in turner syndrome despite signs of accelerated bone resorption. Horm Res Paediatr. 2011; 76 (3): 193-201.

7. Crabtree NJ, Arabi A, Bachrach LK, Fewtrell M, Fuleihan GE, Kecskemethy HH, et al. Dual-Energy X-Ray Absorptiometry Interpretation and Reporting in Children and Adolescents: The Revised 2013 ISCD Pediatric Official Positions. J Clin Densitom. 2014; 17 (2): 225-42.

8. Brandão CMA, Camargos BM, Zerbini CA, Grinberg Plapler P, Maria De Carvalho Mendonça L, Albergaria B-H, et al. Posições oficiais 2008 da Sociedade Brasileira de Densitometria Clínica. Arq Bras Endocrinol Metab. 2009; $53(1)$.

9. Positions O, Society I, Densitometry C, International T, Densitometry C, Conferences PD, et al. 2013 ISCD Combined Official Positions.

10. Zerbini CA, Pippa MG, Eis SR, Lazaretti-Castro M, Mota Neto H, Tourinho T, et al. Densitometria clínica - posições oficiais 2006. Rev Bras Reum. 2007; 47: 25-33.

11. Bachrach LK, Gordon CM. Bone Densitometry in Children and Adolescents. Pediatrics. 2016; 138 (4)

12. Nadeem M, Roche EF. Bone health in children and adolescent with Turner syndrome. J Pediatr Endocrinol Metab. 2012; 25 (9-10): 823-33.

Received on June 11, 2019

Final version presented on May 10, 2021

Approved on August 20, 2021
13. Alghadir AH, Gabr SA, Rizk AA. Physical Fitness , Adiposity, and Diets as Surrogate Measures of Bone Health in Schoolchildren: A Biochemical and CrossSectional Survey Analysis. J Clin Densitom. 2018; 1-14.

14. Tanner JM, Whitehouse RH. Clinical longitudinal standards for height, weight, height velocity, weight velocity, and stages of puberty. Arch Dis Child. 1976; 51 (3): 170-9.

15. Pitukcheewanont $P$, Numbenjapon N, Safani D, Rossmiller S, Gilsanz V, Costin G. Bone size and density measurements in prepubertal children with Turner syndrome prior to growth hormone therapy. Osteoporos Int. 2011; 22 (6): 1709-15.

16. Zuckerman-levin N, Guttmann H, Yaniv I, Schwartz T, Hochberg Z. Normal DXA bone mineral density but frail cortical bone in Turner's syndrome. Clin Endocrinol (Oxf). 2007; 67: 60-4

17. Shaw NJ, Rehan VK, Husain S, Marshall T, Smith CS. Bone mineral density in Turner 's syndrome - a longitudinal study. Clin Endocrinol (Oxf). 1997; 367-70.

18. Bakalov VK, Axelrod L, Baron J, Hanton L, Nelson LM, Reynolds JC, et al. Selective Reduction in Cortical Bone Mineral Density in Turner Syndrome Independent of Ovarian Hormone Deficiency. J Clin Endocrinol Metab. 2003; 88 (12): 5717-22

19. Costa AMG, Lemos-Marini SHV, Baptista MTM, Santos AO, Morcillo AM, Maciel-Guerra AT, et al. Densidade Mineral Óssea: Estudo Transversal em Pacientes com Síndrome de Turner. Arq Bras Endocrinol Metabol. 2002; 46 (2): 143-9.

20. Shi K, Liu L, He YJ, Li D, Yuan LX, Lash GE, et al. Body composition and bone mineral status in patients with Turner syndrome. Sci Rep. 2016; 6: 4-11.

21. Bakalov VK, Bondy CA. Fracture risk and bone mineral density in Turner syndrome. Rev Endocr Metab Disord. 2008; 9 (2): 145-51.

22. Fernández-García D, Rodríguez M, García Alemán J, García-Almeida JM, Picón MJ, Fernández-Aranda F, et al. Thin healthy women have a similar low bone mass to women with anorexia nervosa. Br J Nutr. 2009; 102 (5): 709-14.

23. Morin S, Tsang JF, Leslie WD. Weight and body mass index predict bone mineral density and fractures in women aged 40 to 59 years. Osteoporos Int. 2009; 20 (3): 363-70.

24. Emaus N, Wilsgaard T, Ahmed LA. Impacts of body mass index, physical activity, and smoking on femoral bone loss: The tromsø study. J Bone Miner Res. 2014; 29 (9): 2080-9. 